\title{
Personal Dental Services a practitioner's point of view
}

N. Barker, ${ }^{1}$ and H. Dixon, 2

\author{
NHS dentistry has seen many changes recently. The latest has \\ been the introduction of Personal Dental Services. This article \\ describes the experiences of two general dental practitioners in \\ their practice who entered as a first wave pilot. The article \\ explains the steps involved in generating a proposal and \\ preparing a practice to run as a pilot. The authors have \\ highlighted areas of particular concern for others to consider \\ before embarking on a similar journey.
}

$\mathrm{T}$ he concept of Personal Dental Services (PDS) is to develop a service aimed at meeting specific local need by a contract set up between a health authority (the purchaser) and another body, usually general dental practitioners (the providers and/or performers).

The example involves a small, three surgery general dental practice presently operating in North Essex Health Authority. The service is provided by partners $\mathrm{Dr}$ Nick Barker and Dr Hayden Dixon who have run it since 1994

The Bromley Road Dental Surgery is 2 miles north east of Colchester town centre. The Greenstead housing estate has some 15,000 residents, including 4,000 children. The surgery is situated at its northern boundary. It caters for a high proportion of families from lower socio-economic backgrounds. The nearest dental practice lies 1 mile to the west and has been established for a long time. There are a large number of dental practices in Colchester accepting National Health Service patients, an unusual situation in the present climate.

The 'Health for Greenstead' initiative, a local multi-disciplined political group dedicated to improving conditions in the locality, were keen to incorporate a dental component to their agenda. Communication channels were opened between this group, North Essex Health Authority and the practice to develop ideas on how to

${ }^{1}$ General dental practitioner, ${ }^{2}$ General dental practitioner, Bromley Rd Dental Surgery, 13A Bromley Rd, Colchester, Essex CO4 3JE Correspondence to: $H$. Dixon

REFEREED PAPER

Received 20.05.99; accepted 13.08.99

(c) British Dental Journal 2000; 188: 125-128 improve the oral health of the community. Personal Dental Services appeared to be the natural vehicle to implement this change.

\section{Expression of interest}

The surgery has always been aware of a high incidence of decay in its child patients. It originally attempted to rectify this by approaching several local schools with a view to providing oral hygiene advice. An oral health educator was employed to meet this need. However, after only a few months it became apparent that this service was growing at such a rate that it demanded more and more time and money while generating no income for the practice. A difficult decision had to be made to terminate the service.

In September 1997, the partners met the Consultant in Dental Public Health for North Essex Health Authority. Having considered the idea of providing some form of oral health service under the auspices of PDS, the group decided to submit an expression of interest to the regional office of the

\section{In brief}

- A personal experience of a first wave Personal Dental Service pilot.

- The integration of a dental therapist into a general dental practice.

- The use of an oral health educator to promote better oral health in the local community.

- Targeting preventive treatments to children most at risk.

- Using Personal Dental Services to provide a more comprehensive service to our patients and to develop the practice.
Health Authority.

The expression of interest was accepted and the practice was asked to develop a full business case for which a budget was allocated.

\section{Business case}

Identifying need

The initial requirement was to identify the need in the local population. The practice decided to limit its pilot to the children of Greenstead where need was greatest. The Health and Social Services Institute at Essex University helped to develop a questionnaire that the practice then used to gather data from specific age groups of schoolchildren in chosen schools across the Greenstead estate. This process took the two dentists and the oral health educator 3 clinical days to assimilate the data and one weekend to enter the information into a computer. The University then analysed and reported on this data which revealed a great need for oral health awareness among its subjects.

At the same time, children from these same age groups (5, 12 and 14-year-olds) were being examined at the practice to assess their DMF scores according to the criteria set down by British Association for the Study of Community Dentistry (BASCD). The mean $\mathrm{dmf}$ scores for the average age group (aged 12 years) were $1.29,{ }^{1}$ compared with 0.48 for the North Essex region. ${ }^{2}$ Of these children, $48.9 \%$ had dmf scores of greater than 0 (ie had experienced some decay), compared with only $25.8 \%$ for the whole of North Essex. The data collected on this occasion was sent to the local Community Dental Service to be analysed and reported upon. This, coincidentally, was the start of a good working relationship that allowed these two parties to interact and aim their individual services toward specific and separate targets.

Because of time restraints the children had to be seen during surgery opening hours by the providers. This necessitated training the staff in BASCD scoring which was stimulating for the staff. Seeing these extra patients was, however, a burden on the practice.

Identifying services

In identifying the services required, the 
partners developed a care package aimed at providing treatment to those patients who needed it most, streamlining the service and making it more cost-effective and efficient. The package divided patients clearly into three groups using a combination of DMF score, plaque score and cooperation score. The DMF scoring followed the guidelines set by BASCD, the plaque score used was that described by Silness and Loe in 1963 and the cooperation score was generated by the practice in consultation with the local Community Dental Service.

Discussions with the Health Authority and the Community Dental Service highlighted two services that would enhance what the practice could provide.

An oral health educator was needed to operate both in the surgery and the surrounding community. The educator's work in the surgery environment would be to provide dietary advice and oral hygiene instruction to the child patients of the practice on a one-to-one basis. In the community, they would visit the local schools, cub/scout groups and several other organisations as well as liaising with healthcare workers such as midwives and school nurses. A job description was then clearly set out and included in the business case documentation.

A dental therapist was also to be employed at the practice to provide those treatments most needed. Particular emphasis went on preventive treatments such as fluoride applications, fissure sealing and an enhanced dietary advice and oral hygiene instruction programme.

\section{Identifying costs}

A great deal of time and effort was spent on identifying and then agreeing the costs of running the pilot between the Health Authority and the surgery. Two areas of expense were noted: first, the capital costs involved in both setting up the surgery and growth of the pilot, second ongoing costs to run the pilot. The Health Authority, with a view to any double accounting, examined these ongoing costs very stringently. The costs had to be related to services being provided that were above and beyond those incurred by a surgery operating under the
General Dental Services and must show 'value for money'. After several meetings with the finance department of the Health Authority, many costs were acknowledged but not without much justification. This became tiring at the end of a day's surgery, often adding 5-6 hours to a working week over a period of 2 months. The breakdown of cost headings is shown in Table 1 .

The set up costs were clearly identifiable by reasoning what would be required to commission a surgery for the therapist and purchase the materials that the oral health educator would need to work in the surrounding community. The growth of the pilot would entail a need for greater funding as the number of child patients grew with the increased exposure in the community. The expected growth was calculated by a specific increase in the present rate of growth.

The next step was to go back to the beginning and identify the existing cost of running the practice by generating an income and expense report. By breaking expenses down into categories, areas were found where new or greater costs would be incurred and this was then extrapolated to calculate annual expenses involved solely in running the pilot.

\section{Identifying remuneration}

The monies required to meet the costs would similarly come from two areas. First, the capital costs for setting up the pilot would come from an application to access the money available in the Investing In Dentistry fund. Second, running costs were to be met by a combination of payments from the Dental Practice Board and money added by the local Health Authority. The money provided by the Dental Practice Board was allocated in relation to payments made in the equivalent period the previous year, taking into account any increase in fees. The fund provided by the Health Authority was to meet those extra costs involved in running the pilot. These monies were then added together and held by the Dental Practice Board to be released along existing patterns by requesting payment through transmission of claims. The prime difficulty was allocating capitation payments according to the levels of treatment need. At best this was by estimation of ratios of patient numbers in the three levels that would be further modified once a clearer picture arrived. This calculation was important in order that the full and correct amount of money was accessed over the course of the pilot.

\section{Monitoring}

Monitoring was to take place at two levels. Birmingham University carried out central monitoring for the benefit of the Department of Health. The practice and Health Authority agreed that local monitoring should be conducted by the reference department of the Dental Practice Board along existing guidelines but with a higher proportion of patients being examined.

Monthly meetings were arranged for the steering group (comprising Health Authority staff and the partners) to review and evaluate activity levels and remuneration, and find solutions to any problems encountered.

\section{Exit arrangements}

Finally, conditions were clearly set out to allow an exit by any party from the contract

\begin{tabular}{|clll|}
\hline Table 1 & Ongoing costis & & \\
\hline Wages & $\begin{array}{l}\text { Therapist } \\
\text { Dental Surgery Assistant } \\
\text { Oral Health Educator } \\
\text { Receptionist } \\
\text { Pilot Manager } \\
\text { Dentist's time in meetings }\end{array}$ & Travel & Oral Health Educator \\
Materials & Sundries & $\begin{array}{l}\text { Clinical waste collection } \\
\text { Utilities } \\
\text { Therapist } \\
\text { Oral Health Educator } \\
\text { Pilot Manager }\end{array}$ & $\begin{array}{l}\text { Equipment maintenance } \\
\text { Stationary } \\
\text { Postage }\end{array}$ \\
& & Inflation \\
\end{tabular}


provided certain parameters were met. There was no margin for error in the costing of the pilot, the providers thought long and hard when considering the financial implications that would cause their exit.

\section{The consultation process}

An integral part of developing a Personal Dental Services bid is the process of consultation with the dental profession. This is important on both a local and national level.

Locally, letters were written to the Local Dental Committee, dental practitioners, Community Health Council and the Community Dental Service.

On a wider scale, discussions were held with the British Dental Association, the NHS Executive and the Dental Practice Board.

Representatives from the BDA visited the practice, providing advice and support and reassurance that no serious omissions had been made from the 'business case'.

The NHS Executive met locally with the partners and Health Authority representatives at an early stage. They highlighted areas that needed clarification and offered advice on improvements that could be made. What appeared to be a daunting list of eminent personnel, actually proved to be an enjoyable and enlightening meeting.

Part of the DPB annual conference focussed on new developments within the NHS, namely Personal Dental Services, and as a consequence the partners were invited to participate, outlining the experiences to date and putting the case of the general dental practitioner. This experience was both daunting and challenging but a great opportunity to mix with the 'great and the good' of the dental world. The presentation was successful, fun and educational.

The business case was then sent to the Department of Health for their consideration.

\section{Preparing to run the pilot}

Confirmation that the bid had been successful was received by the end of May 1998.

The positions of oral health educator and therapist needed to be filled as well as many other adjustments to the normal running of the surgery.

\section{Table 2} Role of the pilot manager

1. Weekly meetings with dentists to assess:

- Levels of registration

- Productivity of staff

- Weekly audit of PDS budget; income vs expense

2. Prepare information and meet with Health Authority representatives along with dentists on monthly basis.

3. Weekly meeting with therapist and oral health educator to review and assess past, present and future activities.

4. Weekly contact with local consultation contacts to identify need/activities for oral health educator.

5. Monitor travelling expenses of oral health educator.

6. Calculate wages for oral health educator.

7. Liaise with:

- Essex University and BASCD contacts re re-monitoring of data

- DPB re information reports

- BDA re PDS activities of practice.

- Other PDS pilots

- Media contacts, both professional and social to gain attention for pilot study and heighten practice's public profile.

8. Prepare presentations at post-graduate meetings.

9. Produce PDS newsletter

10. Attend Health for Greenstead meetings.

11. Attend Continuing Development and Education courses.

12. Run complaints service for PDS

Intense and lengthy pricing meetings were a weekly occurrence as the local Health Authority commissioners, accountants and partners went over the initial plans in detail.

\section{NHS executive meeting}

The NHS executive was understandably keen to keep a close watch on the development of the pilot. Consequently, the partners and Health Authority staff were invited to Richmond House to answer questions on financial and other matters and to express confidence, or otherwise, in the practicality of the project.

This experience was not as intimidating as had been anticipated. It was useful to meet the decision-makers face-to-face and exchange views. The Chief Dental Officer and Section Head for Personal Dental Ser- vices from the Department of Health appeared to be happy with the facts and figures to date.

\section{Physical preparations}

Commissioning the third surgery began. This involved time-consuming meetings with various representatives, each with their own ideas of how to put together the basic necessities. Not surprisingly the quotes varied tremendously.

The computer software proved to be a greater problem than had been expected. The problems were due to confusion as to who should pay for the specific changes to the software. Central government funding was initially going to be provided but this was never put in writing. This caused concern for the Health Authority who 
would not be able to afford the additional expenditure. This situation has yet to be fully resolved.

Lengthy discussions spanning 2 months were spent by the partners liaising between the DPB and the software suppliers to ensure that all the criteria were met for the effective running of the scheme and transmission of data. This was more time-consuming than had been anticipated, as the adjustments to the computer software and their interpretation by the DPB had to be synchronized.

Since converting all the registered children to Personal Dental Services meant a change in the way treatment was to be provided, the practice needed to close for staff retraining. The complexities of software adjustments were explained as well as how to cope with the extra number of patients, appointment scheduling and so forth. New staff were brought on board and working hours and responsibilities were shuffled, hopefully to the satisfaction of all concerned. This obviously affected the staff who were used to a set routine. Thankfully the staff were cooperative and appreciated that the benefits to the practice would outweigh the inconveniences. Specific times were made available to the oral health educator and pilot manager to allow them to perform their duties with minimal interruption to the smooth running of the practice. These positions were filled by promoting existing staff members who had expressed an interest in furthering their careers.

Because of increased amounts of data required by the DPB and Health Authority, new roles have evolved that have been assigned to the pilot manager (Table 2).

\section{Benefits}

To justify the amount of time spent in preparing and actioning the business case, the proposed pilot must obviously provide benefits over the existing system.

The benefits to the providers were the employment of auxiliary staff to help in the treatment of difficult child patients. This would further free up the provider's time to undertake more advanced restorative work. There was also a sense of satisfaction and achievement in advancing their professional careers.

The benefits to the practice were to increase the number of registered patients and raise the practice's profile in the local community because of increased exposure through word of mouth and media coverage. Staff also became more integrated in practice life as a consequence of greater teamwork.

The benefits to the patients were a level of service which was specifically targeted at their individual needs with a greater emphasis on prevention of dental disease. The therapist could spend more time with the patient than the dentist would be able to do under the financial constraints in the NHS.

The benefits to the Health Authority were that the practice will meet clear local needs. Further, they could be seen to be acting proactively. The pilot may also prove to be a more cost-efficient service for the NHS.

However, it has been a long and arduous process and brings the practice to an uncertain and pioneering financial position.

\section{Conclusion}

Developing a Personal Dental Services bid has not been an altogether straightforward procedure. It has taken many hours of discussion and hard work. It has, nevertheless, been extremely worthwhile and rewarding, and, retrospectively, a good investment of time and energy.

National Health Service dentistry is not a static entity. Rather, it is evolving as new ideas are developed. Personal Dental Service is but the latest of these developments.

The authors felt it prudent to be a part of this process and contribute in a small way to the future of our profession. Developing a Personal Dental Services bid was never about financial gain. At this stage the authors have found that the careful scrutiny of the finances by the Health Authority has meant that the practice has made neither a financial gain nor a loss. The benefits to the practice have been an increase in the profile of the practice in the local community through media coverage and publicity. A clearer understanding was gained regarding the running of the NHS, which has indirectly led to more efficient management of the practice.

Certainly political, and all responsible opinion, leans to prevention of disease rather than simply dealing with the results of neglect and abuse. The purpose of this pilot is to indicate that prevention and education of a target group is not only immediately cost effective but will have significant long-term cost savings for the public purse.

So, was it all worthwhile? Yes. But the major hitch was the unclear roles of each party in developing this bid. If the authors had it all to do again then a written contract defining tasks and remuneration would be a great benefit.

The authors would like to thank Dr Mark Shackell, Consultant in Dental Public Health for North Essex Health Authority, Dr Andrew Clayton, Dr George Brown of North East Essex Community Dental Services and Julie Powell for their assistance in co-ordinating and correlating statistics, together with advice and encouragement.

1 Data collected and analysed by North East Essex Dental service using Survey Plus.

2 BASCD co-ordinated NHS Dental Epidemiology Programme Caries Prevalence Surveys 1995/6. 